\title{
Medicalisation of female genital mutilation/cutting in Sudan: Shift in types and providers
}

\author{
Nafisa Bedri \\ Huda Sherfi \\ Ghada Rudwan \\ Sara Elhadi \\ Wafa Elamin
}

Follow this and additional works at: https://knowledgecommons.popcouncil.org/departments_sbsr-rh

Part of the Demography, Population, and Ecology Commons, Family, Life Course, and Society Commons, Gender and Sexuality Commons, and the International Public Health Commons How does access to this work benefit you? Let us know!

\section{Recommended Citation}

Bedri, Nafisa, Huda Sherfi, Ghada Rodwan, Sara Elhadi, and Wafa Elamin. 2018. "Medicalisation of female genital mutilation/cutting in Sudan: Shift in types and providers," Evidence to End FGM/C: Research to Help Girls and Women Thrive. New York: Population Council. 


\section{Evidence to End FGM/C}

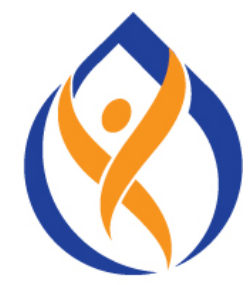

Research to Help Girls and Women Thrive

\section{MEDICALISATION OF FEMALE GENITAL MUTILATION/CUTTING IN SUDAN: SHIFTS IN TYPES AND PROVIDERS}

October 2018 


\title{
MEDICALISATION OF FEMALE GENITAL MUTILATION/CUTTING IN SUDAN: SHIFTS IN TYPES AND PROVIDERS
}

\author{
NAFISA BEDRI \\ HUDA SHERFI \\ GHADA RODWAN \\ SARA ELHADI \\ WAFA ELAMIN
}

GENDER AND REPRODUCTIVE HEALTH AND RIGHTS RESOURCE AND ADVOCACY CENTER

AHFAD UNIVERSITY FOR WOMEN

OCTOBER 2018 
The Evidence to End FGM/C: Research to Help Girls and Women Thrive generates evidence to inform and influence investments, policies, and programmes for ending female genital mutilation/cutting in different contexts. Evidence to End FGM/C is led by the Population Council, Nairobi in partnership with the Africa Coordinating Centre for the Abandonment of Female Genital Mutilation/Cutting (ACCAF), Kenya; the Gender and Reproductive Health and Rights Resource and Advocacy Center (GRACE), Sudan; the Global Research and Advocacy Group (GRAG), Senegal; Population Council, Nigeria; Population Council, Egypt; Population Council, Ethiopia; MannionDaniels, Ltd. (MD); Population Reference Bureau (PRB); University of California, San Diego (Dr. Gerry Mackie); and University of Washington, Seattle (Prof. Bettina Shell-Duncan).

POPULATION COUNCIL

Ideas. Evidence. Impact.
The Population Council confronts critical health and development issues-from stopping the spread of HIV to improving reproductive health and ensuring that young people lead full and productive lives. Through biomedical, social science, and public health research in 50 countries, we work with our partners to deliver solutions that lead to more effective policies, programmes, and technologies that improve lives around the world. Established in 1952 and headquartered in New York, the Council is a nongovernmental, nonprofit organisation governed by an international board of trustees. www.popcouncil.org

GRACe is a leading regional center of excellence on gender and reproductive health and rights; Providing quality resources for all stakeholders, building capacities, promoting evidence-based planning and policy for empowering women and men and promoting reproductive health as a fundamental human right for all. GRACe values are gender equality, women empowerment, integrity, respect for human rights and excellence. It aims to promote gender equality and reproductive health and rights of the community in general and of women in Sudan and the region. www.grace.ahfad.edu.sd

Suggested Citation: Bedri, N., Sherfi, H., Rodwan, G., Elhadi, S., and Elamin, W. 2018. Medicalisation of Female Genital Mutilation/Cutting in Sudan: Shift in Types and Providers. Evidence to End FGM/C: Research to Help Girls and Women Thrive. New York: Population Council.

This is a working paper and represents research in progress. This paper represents the opinions of the authors and is the product of professional research. This paper has not been peer reviewed, and this version may be updated with additional analyses in subsequent publications. Contact: Prof Nafisa Bedri, nmbedri@gmail.com

Please address any inquiries about the Evidence to End FGM/C programme consortium to: Dr Jacinta Muteshi, Project Director, imuteshi@popcouncil.org

Funded by:

This document is an output from a programme funded by the UK Aid from the UK government for the benefit of developing countries. However, the views expressed and information contained in it are not necessarily those of, or endorsed by the UK government, which can accept no responsibility for such views or information or for any reliance placed on them. 


\section{Table of Contents}

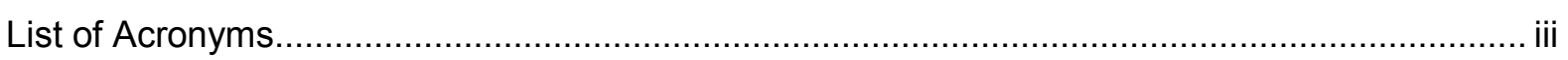

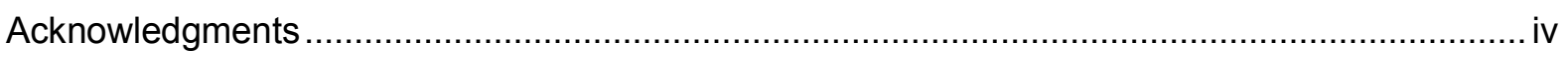

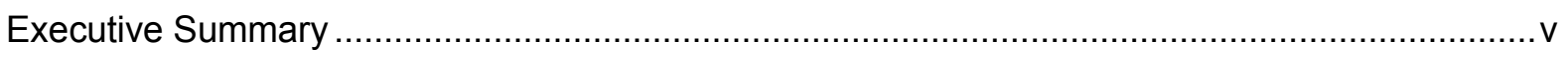

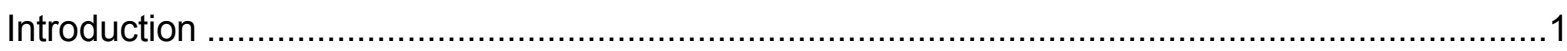

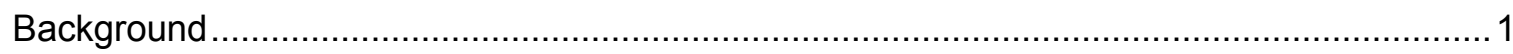

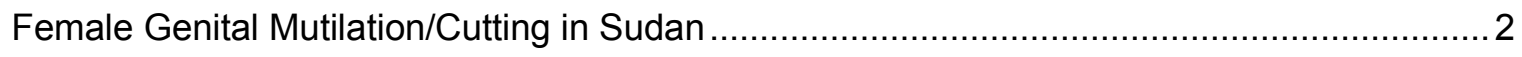

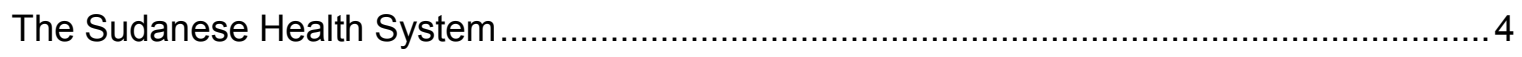

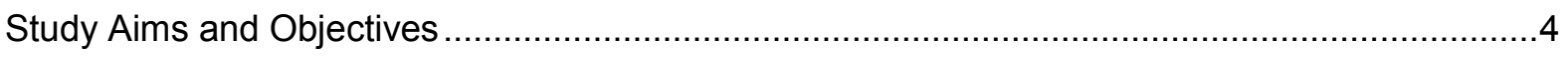

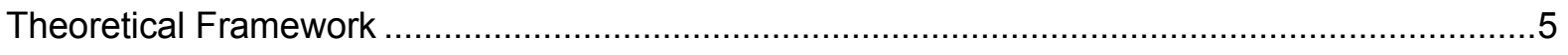

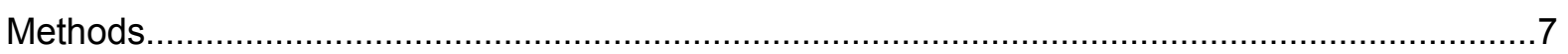

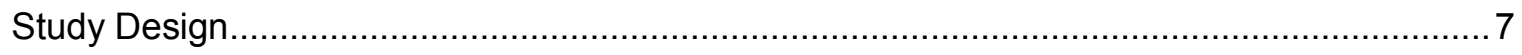

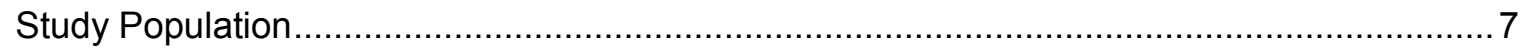

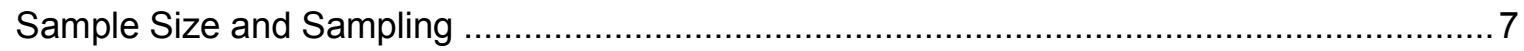

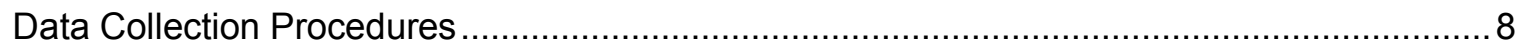

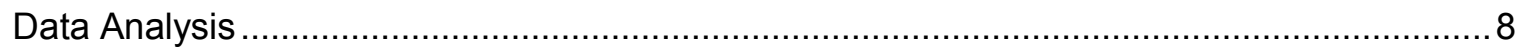

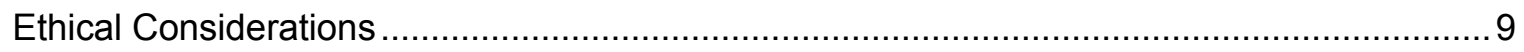

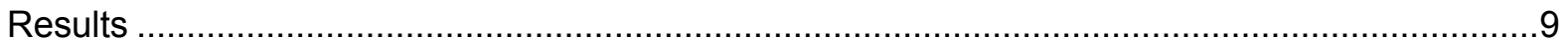

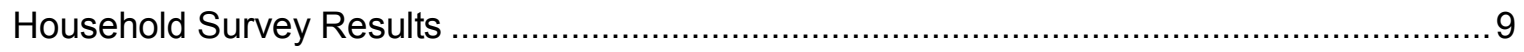

Perceived Reasons why FGM/C Continues to be Practised.............................................. 11

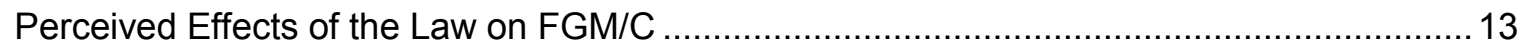

Perceived Effects of the Midwifery Oath on FGM/C........................................................ 13

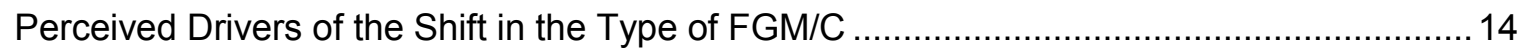

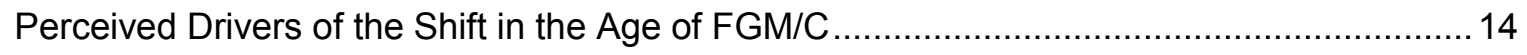

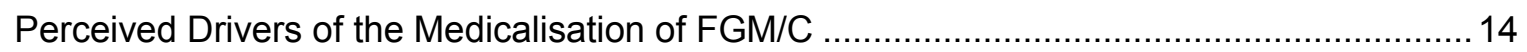

Perceptions of Interventions that are Effective in Reducing Medicalisation and Promoting

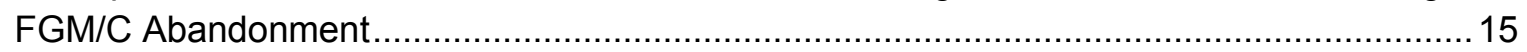

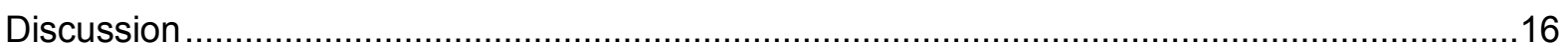

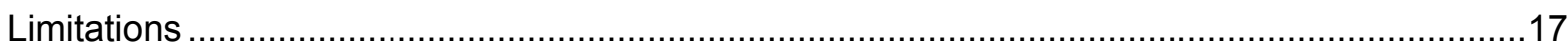

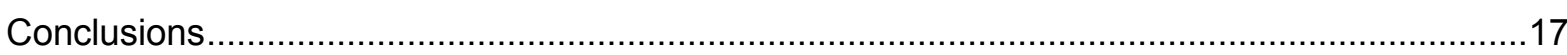

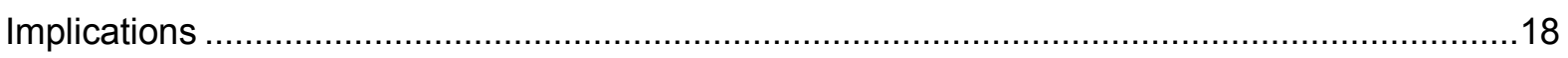

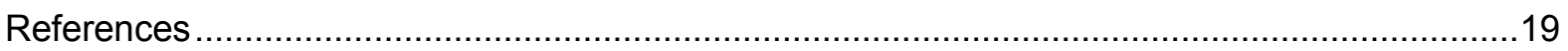




\section{List of Acronyms}

CBS Central Bureau of Statistics

DFID Department for International Development

DHS Demographic and Health Surveys

FGDs Focus Group Discussions

FGC Female Genital Cutting

FGM/C Female Genital Mutilation/Cutting

GRACe Gender and Reproductive Health and Rights Resource and Advocacy Center

HCP Health Care Provider

$\mathrm{HHs} \quad$ Households

IDI In-depth Interviews

MICS Multiple Indicator Cluster Survey

$\mathrm{MoH} \quad$ Ministry of Health

NCCW National Council for Child Welfare

NGO Non-Governmental Organisation

SCCW State Council for Child Welfare

SHHS Sudan Household Health Surveys

SPSS Statistical Package for the Social Sciences

TBAs Traditional Birth Attendants

UN United Nations

UNFPA United Nations Population Fund

UNJP United Nations Joint Program

UNICEF United Nations Children's Fund

VMW Village Midwife

WHO World Health Organization 


\section{Acknowledgments}

The Gender and Reproductive Health and Rights Resource and Advocacy Center (GRACe) at Ahfad University for Women (AUW) would like to recognise and acknowledge the financial support for this work from UK Aid and the UK Government through the DFID-funded project, "Evidence to End FGM/C: Research to Help Girls and Women Thrive," that is coordinated by the Population Council.

The authors would like to express their deepest appreciation to the Umbadda, East Nile, Gedaref and AI Fao localities for their support. Special gratitude is extended to all the key informants from Khartoum and Gedaref States, who had a crucial role in enabling the research team to collect the data and in organising the group discussions.

GRACe would like to thank AUW partners in Khartoum and Gedaref States for their support to the research team. We also extend our gratitude to the Research Programme's Senior Management Team in Nairobi, and Washington D.C., for their overall support and guidance through the overall process of conducting the research and development of the report. We particularly thank Jacinta Muteshi and Caroline Kabiru, Population Council; Tamadur Khalid, Child Protection Officer, UNICEF, Sudan; and Bettina Shell-Duncan, University of Washington, for their expert review and critique of this report, which improved the quality of the final product.

We are extremely grateful to the AUW research team and other researchers in Sudan for their guidance and feedback on this work. 


\section{Executive Summary}

\section{Background}

Although Sudan has had five decades of anti-female genital cutting/mutilation (FGM/C) campaigns, it still has one of the highest prevalence rates in the world. However, the country has seen changes in the practice of FGM/C: a shift from type III (infibulation) to non-infibulating types in some parts of the country and among various ethnic groups, and an increase in the medicalisation of the practice. The magnitude of, and reasons for, these changes are not fully understood. However, recent studies indicate that some supporters of FGM/C believe that less severe cutting addresses the health risks associated with more severe forms of the practice. The change in type is also theorised to have contributed to the increase in the medicalisation of $\mathrm{FGM} / \mathrm{C}$ is presumably facilitated by the lack of strong national laws or regulations that prohibit FGM/C or combat its medicalisation.

\section{Study Goals and Objectives}

This study aimed to inform the development of future interventions by generating evidence on the drivers of the shifts in the practice of FGM/C in Sudan. We conducted a community-based crosssectional, comparative, mixed-methods study that examined shifts in the type of cut, its level and significance, as well as the supply and demand factors associated with medicalisation. We also explored interventions and alternative approaches that may prevent medicalisation and the sustenance of the practice of FGM/C, including re-infibulation.

\section{Methods}

The study was conducted in four localities in Khartoum (Eastern Nile and Umbadda) and Gedaref (Al Fao and Gedaref City) States. Our target populations were families who practised medicalised FGM/C, families that did not practise medicalised FGM/C, and health care providers (HCPs) offering medicalised FGM/C. Samples of traditional birth attendants (TBAs) who are still active providers were also interviewed in rural areas. We conducted a total of 480 household interviews, 58 in-depth interviews (with mothers and midwives), and 13 focus group discussions (FGDs) (four with mothers, three with fathers, three with grandmothers, and three with girls). Data were collected using a semi-structured interview guide and a structured survey instrument. Descriptive statistics were generated using the quantitative data. Qualitative data were analysed through applied coding and memo writing to create categories that represent the participants' perspectives.

\section{Findings}

\section{Less severe cutting and medicalisation}

Household survey results revealed that Gedaref state, which has a law prohibiting FGM/C, had a lower prevalence of type III FGM/C than Khartoum State. However, in both states, less severe forms of cutting were more prevalent. The survey results also showed that the majority of cut girls in both states (86 percent in Khartoum and 79 percent in Gedaref) had been cut by a trained midwife with about two to three percent of girls in both states being cut in health facilities.

\section{Perceived drivers of FGM/C practice}

Interviews with fathers, mothers, grandmothers, and girls revealed that the drivers of $\mathrm{FGM} / \mathrm{C}$ included enhanced marriageability, moving from rural to urban settings where the practice is more prevalent, a perceived male preference for cut girls, and fear of stigma. Internal migration (ruralurban) reportedly has an effect on the uptake of the practice across ethnic groups. Some ethnic 
groups that do not traditionally practise FGM/C reportedly are taking on the practice after arriving in urban cities because of social pressures to integrate into their new settings. In a few instances, even adult women were reported to have undergone FGM/C.

Interviews with HCPs also revealed that FGM/C laws and oaths taken by health providers were also drivers of abandonment, as well as the secret practice, of FGM/C. Other midwives claimed that the high demand from families for FGM/C, their own tradition and beliefs, and social pressure were drivers for the continuation of the practice despite the oath.

Conversely, participants noted that increased educational attainment and awareness efforts/activities were drivers of abandonment in urban areas. Many participants, however, did not articulate their reasons for abandoning the practice. Further, participants noted that men have a key role to play in the decision-making process with regards to the practice and the type of cut. Men can, reportedly, overrule mothers' decisions to cut girls, and a few were reported to demand cutting prior to marriage and even after the honeymoon. Some of the interviewed fathers indicated their support for the practice from a religious perspective, while some young men expressed their willingness to marry uncut women.

\section{Drivers of the shift in the type of FGM/C}

Participants provided various justifications for the shift to less severe forms of FGM/C. Many did not consider the type I cut to be FGM/C. Both men and women described the type I cut as Sunnaa practice approved by religion. They also viewed it as a safer form of FGM/C that had no complications. However, some families believed that it was important for them to continue practising type III FGM/C to conform to traditional beliefs and their identity (i.e., a practice related to their place of origin or ethnicity).

\section{Drivers of medicalisation}

According to participants, the increasing use of HCPs to perform the cut was influenced by reference groups, the availability of practising HCPs, and campaigns that highlighted the health risks of $\mathrm{FGM} / \mathrm{C}$. Although FGM/C is mostly performed by midwives, many mothers expressed a preference for using doctors to perform FGM/C because of their medical knowledge and an assumed decrease in health risks. Further, some participants noted that medicalisation would increase if female doctors performed FGM/C. The use of midwives was also noted to be a vital driver in the shift to less severe forms of the cut and/or abandonment because of the oath that trained midwives are expected to take. Women in rural and urban areas noted that many midwives refused to perform FGM/C, particularly type III, based on this oath with some believing that type I was not FGM/C. However, due to social pressure, the high demand for FGM/C was noted to persist in some areas despite the refusal of some midwives to perform FGM/C. Midwives also expressed fear of being excluded from performing other functions, such as delivery care, if they refused to perform FGM/C. Interviews with mothers also suggest that some of them are protective of HCPs who perform $\mathrm{FGM} / \mathrm{C}$.

\section{Interventions and approaches perceived to be effective in driving FGM/C abandonment and reducing medicalisation}

Participants described interventions and approaches they believed would be effective in driving the abandonment of FGM/C and reducing medicalisation. Some proposed enhancing the role of midwives in campaigns against the practice and focusing on female doctors. Their involvement in medicalisation is perceived to have an impact on the continuation of FGM/C by sustaining the supply side of the practice. To combat FGM/C, and reduce the demand for it, they recommended the involvement of the government and media in promoting FGM/C abandonment, enforcement of 
laws against those who perform $\mathrm{FGM} / \mathrm{C}$, and increased integration of $\mathrm{FGM} / \mathrm{C}$ awareness programmes in schools.

\section{Conclusions}

FGM/C, while still prevalent in Sudan, is undergoing several shifts including changes in the type of cut and increasing medicalisation of the practice. Study findings show that the shift to less severe forms of the cut in some communities is driven in part by social and religious norms coupled with an increased awareness of the health consequences of FGM/C. This awareness also drives the medicalisation of the practice and increases the demand for, and social pressure on, health providers to perform FGM/C. Midwives' refusal to perform FGM/C, particularly type III, is also believed to drive the shift to less severe cutting. Study findings underscore the need for training programmes to increase HCPs awareness of FGM/C and for strong peer support from other health workers to counter the increased demand for medicalisation. Interviews with mothers also suggest that some of them are protective of HCPs who perform FGM/C, which has implications for enforcement of laws targeting providers. Study findings also suggest that while enforcing a punitive law against $\mathrm{FGM} / \mathrm{C}$ may reduce the practice, this could also drive it underground.

\section{Preliminary Implications}

\section{Policy Implications:}

- Continue support for FGM/C abandonment in professional codes of conduct for HCPs.

\section{Programmatic Implications}

- Integrate FGM/C in school curricula and programmes and continue the provision of information of $\mathrm{FGM} / \mathrm{C}$ in the pre-licence training of paramedical personnel and midwives.

- Effectively target men, particularly younger men, in FGM/C abandonment interventions.

- Enhance the training of medical doctors on FGM/C, particularly female doctors, who may face an increased demand for FGM/C services.

- Continued implementation of programmes that increase community awareness on the hazards of all types of FGM/C, including less severe forms of the cut. These programmes should also address the religious underpinnings of the practice, including perceptions that type I FGM/C, or less severe cuts, are Sunna.

\section{Research implications}

- Conduct research among younger men to understand their attitudes towards FGM/C and how they can be effectively reached in FGM/C abandonment programmes.

- Conduct research to identify the positive deviants among providers who have abandoned the practice, their drivers, and the scope of their influence. Whether and how this deviance can be replicated in other contexts should also be investigated.

- Examine how shifts in age of cutting relate to apparent shifts in prevalence in cohorts and interrogate what this means in terms of identifying states with high prevalence for future interventions. 


\section{Introduction}

\section{Background}

Female genital mutilation/cutting (FGM/C) refers to all "procedures that involve partial or total removal or injury of the female external genitalia whether for cultural or any other non-therapeutic reasons" (WHO, UNICEF \& UNFPA, 1997). As of 2016, at least 200 million girls and women, mainly in sub-Saharan Africa and the Arab States, were believed to have been subjected to FGM/C (UNICEF, 2016). In the absence of effective interventions to promote its abandonment, the number of girls cut each year will grow to 6.6 million by 2050 (UNICEF, 2014).

FGM/C is classified into four types (WHO, UNICEF \& UNFPA, 1997):

- Type I: Also known as clitoridectomy (or the Sunna cut in some settings), consists of partial or total removal of the clitoris and/or its prepuce.

- Type II: Also known as excision, consists of the partial or total removal of the clitoris and labia minora with or without excision of the labia majora.

- Type III: Also known as infibulation (or the pharaonic cut in some settings), is the most severe form and consists of narrowing the vaginal orifice with the creation of a covering seal by cutting and positioning the labia minora and/or labia majora, with or without removal of the clitoris. The positioning of the wound edges consists of stitching or holding the cut areas together for a certain period to create the covering seal. A small opening is left for urine and menstrual blood to escape. An infibulation must be opened either through penetrative sexual intercourse or surgery.

- Type IV: Consists of all other procedures to the genitalia of women for non-medical purposes, such as pricking, piercing, incising, scraping, and cauterisation. The World Health Organisation (WHO) includes the practice of introducing substances such as leaves and tree bark into the vagina to reduce lubrication within this category.

The type of procedure performed varies among countries. Globally, in 2005, 90 percent of women older than 15 years who had been cut, indicated having undergone types I (mainly clitoridectomy), II (excision) or IV ("nicking" without flesh removed), and about 10 percent (over 8 million women) had undergone type III, mainly in: Djibouti, Eritrea, Ethiopia, Somalia, and Sudan (Kelly \& Hillard, 2005). Similarly, the age of practice differs among and within countries, with most performing FGM/C on young girls between the ages of four and 14 years (UNICEF, 2013). In some communities, $\mathrm{FGM} / \mathrm{C}$ is practised when a girl is in her teens as a rite of passage from childhood to adulthood (e.g., among the Maasai of eastern Africa), at the time of marriage, or as early as one week old as seen in some ethnic groups in eastern Sudan (Toubia, 1994; UNICEF, 2013).

There are many harmful consequences associated with FGM/C (Berg et al., 2014), which are largely dependent on the type of cut, who performed the procedure, whether sterile instruments are used, and if proper medical care is provided afterwards. In the case of type III FGM/C, additional factors determine the severity of health consequences including the size of the vaginal opening, if surgical thread was used for suturing as opposed to traditional methods such as thorns, and whether the procedure is done repeatedly on the same woman as is common following child birth (re-infibulation) (Abdulcadir et al., 2011). Common immediate complications include local swelling, haemorrhage, pain, urine retention septicaemia, tetanus, gangrene, and infections (Lavazzo, Sardi \& Gkegkes, 2013).

Late complications vary depending on the type of $\mathrm{FGM} / \mathrm{C}$ and may include the formation of keloids, strictures, cysts, hematometra (a medical condition involving collection or retention of blood in the 
uterus that is commonly caused by an imperforate hymen or a transverse vaginal septum), and vesico-vaginal fistulae (Rushwan, 2013). FGM/C may increase a woman's risk of death during pregnancy and labour, particularly for those who have undergone severe forms of the cut since cervical evaluation during labour may be difficult and labour may be prolonged or obstructed. Anxiety, depression, and post-traumatic stress disorder may also develop with time.

A multi-national study conducted in 2006 by the WHO that targeted 28,393 women attending delivery wards at 28 obstetric centres in Burkina Faso, Ghana, Kenya, Nigeria, Senegal, and Sudan estimated that $10-20$ babies out of every 1,000 deliveries died because of FGM/C (Banks et al., 2006). Further, neonatal death rates were found to be higher among those whose mothers had undergone FGM/C compared to uncut women. Specifically, deaths were 15 percent higher in mothers with type I, 32 percent higher in those with type II, and 55 percent higher for those with type III cutting. FGM/C was associated with an increased risk of damage to the perineum and postpartum haemorrhage, the need to resuscitate the baby, and stillbirth in cases where prolonged second stage of labour occurred (WHO, 2006).

$\mathrm{FGM} / \mathrm{C}$ is a deeply rooted practice that is held in place by beliefs around preserving a girl's purity and modesty and controlling women's sexuality. It is usually initiated and carried out by elder female members of the family, who view it as a source of honour. They fear that failing to have their daughters and granddaughters cut will expose them to social stigmatisation and reduce the girls' chances of marriage (UNICEF, 2013). There are several socio-cultural factors associated with the practice (WHO, 2017), which include preparing the girl for adulthood and marriage, protecting the girl's virginity and preventing marital infidelity by reducing her libido, especially in cases with severe types of cutting. FGM/C is also associated with cultural notions that girls are clean and beautiful after the removal of body parts that are considered unclean, unfeminine, or male.

Globally, most girls and women are cut by traditional practitioners, traditional birth attendants (TBAs) and, generally, older members of the community, usually in the women or girls' homes, with or without anaesthesia. This is true for over 80 percent of the girls who have undergo the practice in Benin, Burkina Faso, Côte d'Ivoire, Eritrea, Ethiopia, Guinea, Mali, Niger, Tanzania, and Yemen. In most countries, medical personnel, including doctors, nurses, and certified midwives, are not widely involved in the practice (UNFPA \& UNICEF, 2014). When traditional circumcisers are involved, non-sterile cutting devices including knives, razors, or glass may also be used (Odukogbe, Afolabi, Bello, \& Adeyanju, 2017).

When FGM/C is performed by a medical professional it is referred to as the "medicalisation" of $\mathrm{FGM} / \mathrm{C}$. Globally, it is estimated that more than 18 percent of FGM/C procedures are performed by medical professionals; however, medicalisation rates across countries vary between one percent and 74 percent (Pearce \& Bewley, 2014). Although medicalisation may reduce the risk of complications, it does not eliminate them, nor does it change the fact that FGM/C remains a violation of girls' and women's right to life, physical integrity, and health. Further, when FGM/C is performed by a health professional who usually holds a position of power, the practice is reinforced and institutionalised (Serour, 2010).

\section{Female Genital Mutilation/Cutting in Sudan}

Despite five decades of anti-FGM/C campaigns, with a national FGM/C prevalence of 86.6 percent among women aged 15-49 years, and 31 percent among girls younger than 15 years, Sudan still has one of the highest prevalence rates in the world (Central Bureau of Statistics [CBS] \& UNICEF Sudan, 2016). Although the prevalence remains high, there have been several changes in the practice. The first is the shift in the type of cut practised in various parts of the country, and among various social groups from the so-called pharaonic (type III) cut to what is often called the Sunna 
(presumably type I) cut (Gamal \& Hussein, 2013). The use of the term Sunna-words and actions that are attributed to the Prophet Mohammed (PBUH) and that underpin Islamic religious teachings (Gibeau, 1998)—reflects a strong argument that links FGM/C to Islam. Despite efforts directed towards setting a solid religious stance against FGM/C through public declarations made by religious and traditional leaders to delink religion from the practice, it is still widely believed to be a religious obligation in Sudan (UNFPA \& UNICEF, 2014). Recent research indicates that, among other factors, the focus of anti-FGM/C campaigns over the last decades on the compelling medical evidence that emphasises the health risks of $\mathrm{FGM} / \mathrm{C}$ may also have played a key role in driving this change. As a less severe form of cutting, for the supporters of the continuation the $F G M / C$, Sunna cuts are believed to avert the health risks associated with more severe forms of the practice.

Concerns about the health risks may have also contributed to the second shift in the practice-the medicalisation of FGM/C. The 2014 Multiple Indicator Cluster Survey (MICS) found that 58 percent of cut girls aged 10-14 years in Sudan were cut by a trained health care provider (HCP) (CBS \& UNICEF Sudan, 2016). The MICS secondary analysis report showed an increase in the medicalisation of the practice where the percentage of women aged 15-49 years cut by a trained midwife increased over time from 69 percent between 1990-1999 to 76 percent in the years 20002014 (UNICEF, 2016). The lack of strong national laws or regulations that prohibit the practice, or combat its medicalisation, may limit the success of abandonment programmes (Toubia, 1994).

The third shift is the change in the age of cutting. Secondary analysis of the 2014 MICS showed a 50 percent increase in the proportion of girls cut at age ten years and older between 1980-1989 and 2000-2014 (10.1 percent in 1980-1989 compared to 23.1 percent in 2000-2014) (UNICEF, 2016). Further, a significant decrease in the proportion of girls cut when they were four years or younger was reported in the two periods (13.2 percent in 1980-1989 and 4.7 percent in 20002014).

Outreach groups have been trying to eradicate the practice for 50 years, working with nongovernmental organisations (NGOs), religious groups, the government, the media, and medical practitioners. Community-based initiatives to combat FGM/C started in the 1970s in Sudan and evolved to more focused campaigns using social norms change and social marketing to address beliefs and norms sustaining the practice. These include the Saleema campaign, which started in 2008 to help in marketing the value of the uncut girl, and the Mercy and Compassion (Almawada wa Al-Rahma) campaign established by the National Council for Child Welfare (NCCW) and UNFPA Sudan office building on existing religious conventions of mercy and compassion in family relationships, including parental ones towards young girls. In 2013, the Sudan Free from FGC Programme was initiated by the NCCW with support from the UK Department for International Development (DFID) and three UN partners (UNICEF, UNFPA, and WHO). The programme's goal is a Sudan free from $F G M / C$ in a generation.

Currently there is no national law banning $F G M / C$, although legal restrictions have been implemented at times in Sudan's history. In 1946 Sudan was the first country to ban FGM/C, but this was revoked in the 1980s. Type III was prohibited under the 1925 Penal Code, with less severe forms allowed. Between 2008-2010 several movements to enhance the legal environment resulted in the enactment of four state-level laws banning FGM/C (UNICEF, 2013; PRB 2013). Further, in September 2016, an amendment to the Criminal Act (1991) was approved by the Council of Ministers to criminalise FGM/C but is still pending endorsement by parliament ( 28 Too Many, 2018). There is no evidence of reported arrests or legal cases in the four states with laws against FGM/C (28 Too Many, 2018). 


\section{The Sudanese Health System}

Sudan is a country that is unique and complex in its climate, politics, environment, languages, cultures, religion, and ethnicities, and has suffered from several challenges over the years including conflict and social, economic, and political instabilities. The overall health indicators in Sudan are comparable to sub-Saharan Africa averages. However, overall averages mask significant urban-rural and regional disparities, related to conflict, displacement, and chronic poverty. For example, the average skilled birth attendance stands at 23 percent; but is 40 percent in urban areas and approximately 17 percent in rural areas (UNFPA, 2014).

Health care services are provided through the public and private sectors and institutions allied to health. Services are then categorised into primary, secondary, and tertiary care. The Sudanese government has instituted different programmes to address the unequal distribution of health care services. These programmes include the training of midwives to address the unequal distribution of health workers. The Roadmap for Reducing Maternal and Child Mortality in Sudan (2010-2015) identified midwives as key actors in combating FGM/C. In 2015, the Federal Ministry of Health introduced a module on FGM/C and its management. Among the five categories of health providers trained on midwifery, or midwifery-related services, are village midwives (VMWs), who undertake a 1-year certified programme and provide hands-on care at community and health unit level. A study by UNFPA in 2011, on effective deployment and performance of graduate VMWs, indicated that the reduction in $\mathrm{FGM} / \mathrm{C}$ prevalence could be attributed to a newly introduced oath for not practising FGM/C for VMWs, the expansion in their training and their distribution. The study noted, however, that VMWs often face cultural, economic, and religious barriers to providing anti-FGM/C messages or counselling. They often feel trapped by their economic constraints, perceptions that $\mathrm{FGM} / \mathrm{C}$ is an important part of the culture, and their knowledge of the harm the practice poses to girls' and women's wellbeing (UNFPA, 2011). Thus, while the oath was intended to change social norms among health professionals, the norms among the professionals may come into conflict with the personal social norms of the midwives and their sense of duty or loyalty to their patients, who still request for, and value, $\mathrm{FGM} / \mathrm{C}$.

\section{Study Aims and Objectives}

The magnitude of the shifts in the practice of $F G M / C$ and its drivers are not fully understood as existing large-scale surveys do not provide data on the prevalence of FGM/C by clinically affirmed type but by self-reports. For example, the 2014 MICS introduced two sets of questions that asked women if any flesh was removed or any part sewn. However, these questions do not help distinguish between the three types of the cut since in all three types cutting and sewing may be done. Conducting a community study that interrogates the shifts in the practice of $\mathrm{FGM} / \mathrm{C}$, the drivers of these shifts, and their inter-linkages is fundamental for improving our understanding of the current situation in the country, and for informing and strengthening abandonment interventions. This study therefore sought to:

- Investigate shifts in the type and age of cutting and medicalisation in different contexts and social groups in two states in Sudan;

- Understand the drivers and factors associated with the shift in type, medicalisation, and age of cutting; and

- Explore interventions and alternative approaches that may prevent medicalisation and promote abandonment.

The primary research questions that we sought to answer were:

- At what age are girls cut and is there a shift in the age at cutting? 
- What type of FGM/C do girls undergo and is there a shift in the type?

- What is the association between parental education, socio-economic, religion, and social pressure and the type of FGM/C and medicalisation?

- What are the main drivers and factors driving shifts in the type of FGM/C and medicalisation?

- What are the attitudes of families towards performing less severe cutting or not cutting at all?

- What are the attitudes of different health providers towards performing less severe cutting or not cutting at all?

- What interventions and different approaches do families and health providers think can influence their choices and practice of medicalisation?

\section{Theoretical Framework}

Family honour and social expectations play a powerful role in perpetuating $\mathrm{FGM} / \mathrm{C}$, making it extremely difficult for individual families, as well as individual girls and women, to stop the practice on their own. Even when parents recognise that FGM/C can cause serious harm, the practice persists because they do it from a stance of love and protection for their daughter, and for fear of moral judgments and social sanctions should they decide to break with society's expectations (Cook, Dickens, \& Fathalla, 2002). Therefore, FGM/C is not only a social convention, it is also a social norm-a rule of behaviour that members of a community are expected to follow, and are motivated to follow, through a set of rewards, such as higher chances of marriageability, and negative sanctions, such as social exclusion and stigmatisation (UNICEF \& European Union, 2010). Adhering to a community's social norms is therefore important, not only to maintain an individual's acceptance and social status in the community, but also to preserve the status of the individual's family.

The reasons for the practice in Sudan do not differ from those in neighbouring countries, and include religious reasons, increasing girls' marriageability, and protecting their virginity. $F G M / C$ is also believed to give the husband greater sexual pleasure, thus giving the woman more power to sexually manipulate the man for material benefits (Bedri, 2013). On the other hand, FGM/C is thought to control women's sexuality and reduce the female libido, thus saving her chastity, ensuring that she is not sexually demanding nor likely to commit adultery. Female's cleanliness, femininity, and beauty are also believed to be enhanced by FGM/C as it involves the removal of the clitoris, which is perceived to be "masculine", or in the case of infibulation, enhances the smoothness of the genitals, which are considered to be beautiful.

Different theoretical lenses can help to explain the complex relationships between the different motives behind the practice of FGM/C. Because of the social structure of Sudanese communities and the position of HCPs, particularly midwives, who are the main providers of medicalised FGM/C, we drew on the social norm theory as a theoretical framework to examine the drivers of $F G M / C$ among both family members and HCPs.

The main factors that are known to accelerate a community's readiness to abandon or discontinue the practice are: understanding its health consequences, conviction that $F G M / C$ is not a religious requirement, existence of an operationalised law to criminalise the practice (unless it drives the practice underground), and living in a community that rejects or does not practise FGM/C. These factors may operate at various levels independently or at the same time but interdependently (i.e., more than one factor working together) to influence the decision to practise among the different actors, including HCPs. Having said that, it is essential to consider the role of the social network and the community to which the individual and the family belongs, as their opinion, perception, and 
practices may very well override individuals' intentions. As such, being part of a community that supports and rewards the practice will challenge any individual abandonment attempts, even if one de-links FGM/C from religion, understands the health risks, and an operational law exists. Thus, HCPs who are against the practice may need to be assured that enough of their peers (other HCPs) hold similar sentiments before they can publicly express their desire not to perform $\mathrm{FGM} / \mathrm{C}$. Having relatively few HCPs in a practising community where there is high demand may also challenge HCPs' position not to perform (supply) FGM/C because of the potential loss of income, or concerns that the community may turn to unskilled providers. Figure 1 below summarizes the factors that influence social change in the practice of FGM/C.

Figure 1. Factors that influence social change in the practice of FGM/C

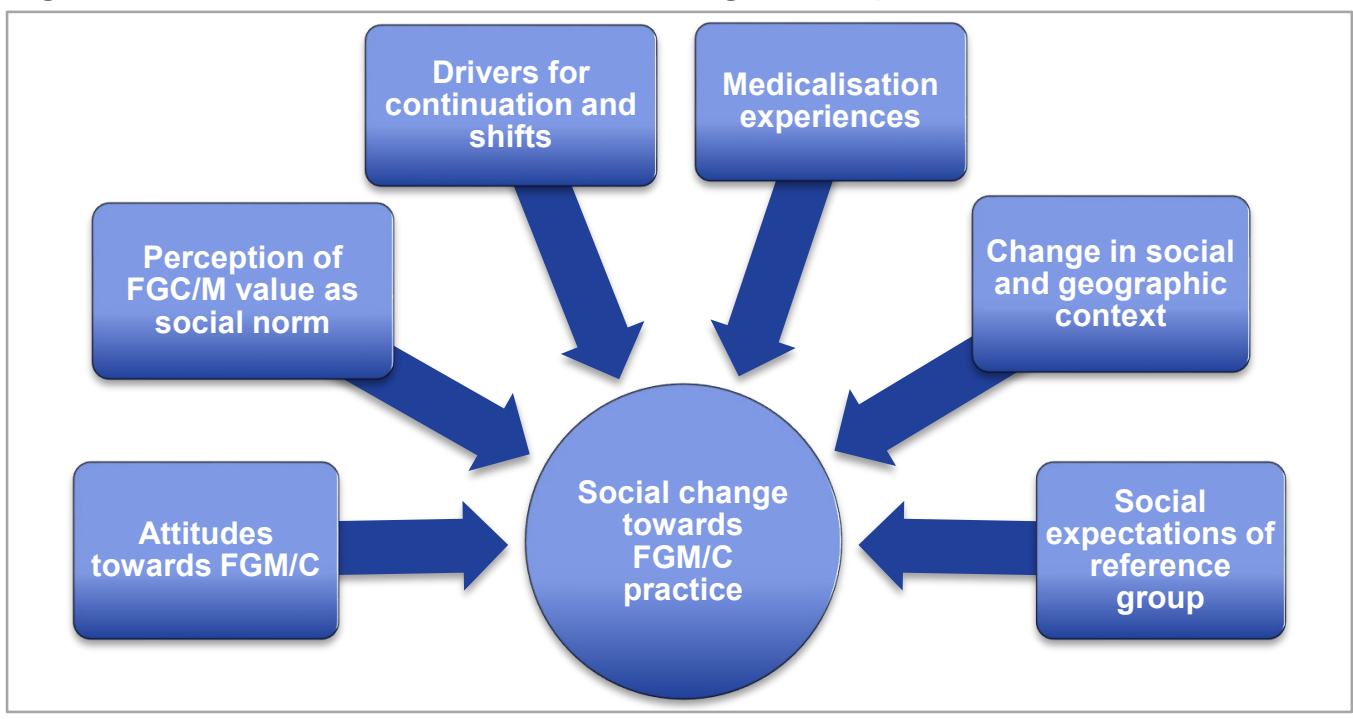

We applied social norms theory by examining:

- Individual family members' and HCPs' personal attitudes towards FGM/C and trends in the type of cutting;

- Individual family members' and HCPs' perceptions about FGM/C and trends in the type of cutting;

- Families' and HCPs' social expectations (who and what others in reference group do, prefer to do, and expect them to do);

- Whether families and HCPs think others are practicing medicalisation, and how many are seeking HCPs or are other HCPs cutting (empirical experience); and

- Individual family members' and HCPs' perceptions about why people would want to use a HCP, whether they approve of HCPs performing FGM/C, and whether HCPs counsel families not to cut their daughters (normative experience).

We posit that the medicalisation of $\mathrm{FGM} / \mathrm{C}$ creates implicit approval of the practice, which may sustain it and its performance by non-HCPs. Medicalisation may also lead to a total shift rather than abandonment. Further, we posit that the shift in the type of FGM/C and medicalisation are driven by support for the continuation by families (demand) and HCPs (supply). Due to the social gains and positive social sanctions expected by HCPs for their service, HCPs continue to provide these services. Families are also thought to be motivated by social, moral, religious, and legal norms. 


\section{Methods}

\section{Study Design}

We conducted a community-based, cross-sectional, comparative, mixed-methods (qualitative indepth interviews [IDIs] and focus group discussions [FGDs] and quantitative household surveys) study that examined shifts in the type of cut, its level and significance, as well as the supply and demand aspects of medicalisation. We also explored interventions and alternative approaches that may prevent medicalisation and sustenance of FGM/C practice, including re-infibulation.

\section{Study Sites}

This study was conducted in Khartoum and Gedaref. These two states were selected because of their variable medicalisation rates identified in the 2010 Sudan Household Health Survey (SHHS). Khartoum State had a higher medicalisation rate in 2010 , with 1.2 percent of FGM/C performed by doctors, 56 percent by nurses or midwives, and 42 percent by traditional midwives, compared to zero percent by doctors, 28 percent by nurses or midwives, and 67 percent by traditional midwives in Gedaref State. Results of the 2014 MICS showed an increase in the utilisation of trained midwives with 89.1 percent and 41.6 percent of girls and women in Khartoum and Gedaref, respectively, cut by these providers.

Khartoum State was also selected for its diverse population, which represents almost all ethnic groups in Sudan, and the presence of several actors working to combat FGM/C. Despite having lower percentages of medicalisation, Gedaref State also has a diverse population and a variety of initiatives aimed at combating FGM/C. Both states have midwifery schools, several medical schools between them, and each has an Academy of Health Sciences. In addition, midwives practising in both states are required to take an oath not to practise FGM/C. The study was conducted in four localities, two in Khartoum (Eastern Nile and Umbadda) and two in Gedaref (AI Fao and Gedaref City) States.

\section{Study Population}

Our target populations were families who practised medicalised FGM/C, families that did not practise medicalised FGM/C, HCPs offering medicalised FGM/C, and TBAs (TBAs are not trained midwives but still perform FGM/C and people do seek their advice). To gain a comprehensive understanding of the perceptions and experiences of different family members, within each family, we separately interviewed the mother, father, an older sibling, the girl herself (if older than 18), and grandmother (if available).

The families for the qualitative interviews were identified from the household survey database. To be eligible, families had to have two daughters who had been cut, with a minimum five-years age difference and the youngest being below ten years of age. In Khartoum, where too few families were identified through the database, additional families were recruited through snowball sampling with the help of key informants from partner organizations (universities, NGOs, women's groups formed by the Gender and Reproductive Health and Rights Resource and Advocacy Center (GRACe), and community-based organisations working on FGM/C).

\section{Sample Size and Sampling}

For the household survey, probability sampling was used as we were seeking families with at least two cut girls who are at least five years apart in age, with the youngest being below ten years of age. The respondents were mothers or grandmothers of the girls. A minimum sample size of 230 households per state was considered adequate (Cochrane, 1977). Households were selected 
using a stratified, two-stage sampling design. In the first stage, we selected a sample of clusters (localities, administrative units, popular administrative units), one urban and one rural from each state, from units identified by the DFID-supported Sudan Free from FGC Programme. In the second stage, we systematically selected, with equal probability, 60 households from each selected cluster by selecting every third household. Sampling for the qualitative interviews was carried out until data saturation or information redundancy was achieved.

\section{Data Collection Procedures}

The household survey was conducted in November and December 2016 to identify families with at least two cut girls. Those that demonstrated a shift in the type of cut were recruited for the study. The survey's respondents were the mothers or grandmothers of the girls from 240 households in each state.

Qualitative data were collected between January and March 2017. In Khartoum State, the data collection was done in collaboration with the heads of the health sectors in the localities and the local committees in the targeted/selected communities. The local committees supported the research team by identifying key informants from the communities, selecting suitable communities for data collection based on criteria outlined by the research team, and bringing together families for the FGDs and IDIs.

In Gedaref, the data collection was done in collaboration with the State Council for Child Welfare (SCCW), a governmental institute. The SCCW served as an entry point and assisted the research team in getting the requisite permission from official state authorities to start data collection, contacting the local community leaders in targeted communities, and supporting data collection by providing two trained data collectors for the FGDs.

A total of 27 IDIs ( 15 with mothers and 12 with midwives), and five FGDs ( 2 with mothers, 1 with fathers, 1 with grandmothers, and 1 with girls older than 18 years) were conducted in Khartoum State. A total of 31 IDIs (18 with mothers and 13 with midwives), and eight FGDs (2 with mothers, 2 with fathers, 2 with grandmothers, and 2 with girls older than 18 years) were conducted in Gedaref State. Each FGD comprised 8-12 participants. In one locality in Khartoum State (Umbadda), we were unable to conduct FGDs with daughters and grandmothers because of the few number of participants available.

Focus group discussions were held in venues selected in consultation with the participants. Participants sat in circles to facilitate discussion. The interviews and discussions lasted about one to two hours and were audio-recorded. Discussions and interviews were guided by semi-structured interviews guides and conducted in Arabic. The questions were mainly about the age of the cut, shift in the type of FGM/C, and the performer.

\section{Data Analysis}

Household survey data were analysed using Statistical Package for the Social Sciences (SPSS) 20.0. Simple descriptive statistics and cross-tabulation were computed to identify cases where a shift in the type of cutting or performer of the cutting existed and the patterns of change. Variables analysed were the age at cutting, type of cut, performer, and place where FGM/C was carried out. Results are presented in tables.

Audio files from the IDIs and FGDs were transcribed in Arabic taking into account non-verbal cues. To obtain reliability and trustworthiness, each audio file was transcribed by two transcriptionists working independently. The final transcripts were then read to identify key codes and themes using content analysis. Key codes, themes, and quotations were translated into English. Exemplar quotes that were drawn from the interviews and FGDs were used to illustrate significant findings. 


\section{Ethical Considerations}

Ethical approval for the study was granted by the Population Council's Institutional Review Board and the Ahfad University for Women's Research Committee. Informed consent was obtained from participants prior to the interviews and hard copies of the consent forms were stored in a secure location only accessible to the research team. All audio recordings and transcripts were stored on password-protected computers and audio recordings were deleted after their contents had been fully transcribed and analysed. Data were fully anonymised.

\section{Results}

\section{Household Survey Results}

This section summarises the results from the household survey. Key findings are summarised in Table 1. A total of 480 households participated in the surveys. These households had a total of 513 and 569 females in Khartoum and Gedaref States, respectively. Adolescent girls and young women aged 11 to 25 years comprised 45 percent of all females, while girls aged five to ten years comprised about one-third of all females.

Fifty-six percent of women had undergone FGM/C. Of all women who reported that they had undergone FGM/C, 56 percent had undergone the Sunna cut. In Khartoum State, 50 percent of the females who had undergone FGM/C were cut between the ages of one and six years, while in Gedaref State, 69 percent were cut at the same age. The majority of women in Khartoum (86 percent) and Gedaref (79 percent) States were cut by a trained midwife. Five percent of women in Gedaref were cut by a health visitor (a graduate of a two-year program after nurse-midwife certification, who primarily provides antenatal care and family planning at the facility level). In Khartoum State, 76 percent of females were cut in their family homes, 12 percent at the providers' house, and two percent in a health facility (clinicalisation). Similarly, in Gedaref State, two percent were cut in a health facility, six percent in the performer's house, while most females (68 percent) were cut at the family home.

Table 1. Descriptive characteristics of females who had undergone FGM/C in Khartoum and Gedaref States

\begin{tabular}{|c|c|c|c|c|c|c|}
\hline & Khartoum & & Gedaref & & Total & \\
\hline & $\mathrm{N}$ & $\%$ & $\mathrm{~N}$ & $\%$ & $\mathrm{~N}$ & $\%$ \\
\hline Number of households & 240 & & 240 & & 480 & \\
\hline Number of females (excluding mothers) & 513 & $70 \%$ & 569 & $80 \%$ & 1,082 & $75 \%$ \\
\hline$\%$ calculated from total number females & & & & & & \\
\hline \multicolumn{7}{|l|}{ Age $(\%)$} \\
\hline$<5$ years & 47 & $9 \%$ & - & - & 47 & $4 \%$ \\
\hline $5-10$ years & 139 & $27 \%$ & 205 & $36 \%$ & 344 & $31 \%$ \\
\hline $11-25$ years & 231 & $45 \%$ & 267 & $47 \%$ & 498 & $46 \%$ \\
\hline $26-40$ years & 46 & $9 \%$ & 84 & $15 \%$ & 130 & $12 \%$ \\
\hline$\geq 41$ years & 27 & $5 \%$ & 3 & $1 \%$ & 30 & $3 \%$ \\
\hline Don't know & 23 & $4 \%$ & 10 & $2 \%$ & 33 & $3 \%$ \\
\hline \multicolumn{7}{|l|}{ FGM status (\%) } \\
\hline Cut & 288 & $56 \%$ & 315 & $55 \%$ & 603 & $56 \%$ \\
\hline Uncut & 225 & $44 \%$ & 254 & $45 \%$ & 479 & $44 \%$ \\
\hline
\end{tabular}


Table 1. Descriptive characteristics of females who had undergone FGM/C in Khartoum and Gedaref States

\begin{tabular}{|c|c|c|c|c|c|c|}
\hline & Khartoum & & Gedaref & & Total & \\
\hline & $\mathrm{N}$ & $\%$ & $\mathrm{~N}$ & $\%$ & $\mathrm{~N}$ & $\%$ \\
\hline \multicolumn{7}{|l|}{ Age at cutting* } \\
\hline $1-3$ years & 45 & $16 \%$ & 132 & $42 \%$ & 177 & $30 \%$ \\
\hline 4-6 years & 99 & $34 \%$ & 84 & $27 \%$ & 183 & $31 \%$ \\
\hline $7-9$ years & 69 & $24 \%$ & 66 & $21 \%$ & 135 & $22 \%$ \\
\hline $10-12$ years & 39 & $16 \%$ & 17 & $5 \%$ & 56 & $9 \%$ \\
\hline Don't know & 36 & $10 \%$ & 16 & $5 \%$ & 52 & $8 \%$ \\
\hline \multicolumn{7}{|l|}{ Type of cut ${ }^{*}$} \\
\hline Sunna & 169 & $59 \%$ & 167 & $53 \%$ & 336 & $56 \%$ \\
\hline Pharaonic (Type III) & 91 & $32 \%$ & 74 & $23 \%$ & 165 & $27 \%$ \\
\hline Others & 7 & $2 \%$ & 27 & $9 \%$ & 34 & $6 \%$ \\
\hline Don't know & 21 & $7 \%$ & 47 & $15 \%$ & 68 & $11 \%$ \\
\hline \multicolumn{7}{|l|}{ Person performing the cut ${ }^{*}$} \\
\hline Doctor & 5 & $1.7 \%$ & 1 & $0.7 \%$ & 6 & $1 \%$ \\
\hline Nurse & 2 & $1 \%$ & 4 & $1.3 \%$ & 6 & $1 \%$ \\
\hline Trained midwife & 248 & $86 \%$ & 249 & $79 \%$ & 497 & $82 \%$ \\
\hline Health Visitor & 1 & $0.03 \%$ & 17 & $5 \%$ & 18 & $3 \%$ \\
\hline Others (Traditional birth attendant) & 9 & $3 \%$ & 44 & $14 \%$ & 53 & $9 \%$ \\
\hline Don't know & 23 & $8 \%$ & - & - & 23 & $4 \%$ \\
\hline \multicolumn{7}{|l|}{$\begin{array}{l}\text { Location where the cut was } \\
\text { performed* }\end{array}$} \\
\hline Family's home & 218 & $76 \%$ & 213 & $68 \%$ & 431 & $71 \%$ \\
\hline Providers' home & 34 & $12 \%$ & 19 & $6 \%$ & 53 & $9 \%$ \\
\hline Health facility & 6 & $2 \%$ & 10 & $3 \%$ & 16 & $3 \%$ \\
\hline Others & 6 & $2 \%$ & 7 & $2 \%$ & 13 & $2 \%$ \\
\hline No response & 24 & $8 \%$ & 66 & $21 \%$ & 90 & $15 \%$ \\
\hline
\end{tabular}

${ }^{*}$ Among cut women and girls

Information on the type of cut performed on girls and young women $(<20$ years old $)$ in the households is summarised in Table 2. Forty-seven percent $(n=242)$ of young women had been cut. Among these young women and girls, 75 percent of them had reportedly undergone the Sunna cut.

Table 2. FGM/C status of girls and young women ( $<20$ years) in Khartoum and Gedaref States $(\mathrm{N}=515)$

\begin{tabular}{|lrr|}
\hline Variable & n & Percent \\
\hline FGM/C Status & & \\
$\quad$ Cut & 242 & $47 \%$ \\
$\quad$ Uncut & 273 & $53 \%$ \\
Type of cut (n=242) & & \\
$\quad$ Pharaonic (Type III) & 31 & $13 \%$ \\
Advanced Sunna & 13 & $5 \%$ \\
(Sandwich) & & \\
Sunna & 180 & $75 \%$ \\
Other & 5 & $2 \%$ \\
Don't know & 13 & $5 \%$ \\
\hline
\end{tabular}




\section{Perceived Reasons why FGM/C Continues to be Practised}

Social and gender aspects emerged as major reasons for the continued practice of FGM/C. The most common reason given by all categories of participants was marriageability. Two important elements of marriageability were highlighted, being able to get a husband and being able to maintain the marriage. With respect to the former, participants highlighted the fear of uncut, young women being unable to find husbands or the shame of having an unmarried daughter. These views are illustrated in the following quotes from participants:

"We cut our daughter because men will reject them."

Father, rural Khartoum State

"No one marries an uncut girl."

Midwife, urban Khartoum State

With respect to the perceived importance of $\mathrm{FGM} / \mathrm{C}$ in maintaining a marriage, participants noted that men are happy when their wives are cut. As one father from rural Gedaref explained, "The cut girls are more beautiful than the uncut girls. Men prefer them." Others noted that an uncut wife would be returned to her family after marriage to be cut, causing her shame. Families were reported to cut their girls because mothers fear that their daughter might be subjected to divorce or separation. This view is highlighted in the following quotation from a woman in rural Gedaref State:

"Even if the mother is convinced not to cut her daughters, the grandmother will say to you, 'these are our traditions and in the past, we do not leave her it is bad on us if she stays like this [uncut].' And they say to you, 'who will marry her?' And the men will not accept an uncut girl. They give you an example of a girl who was returned to her family after the wedding as she was not cut."

Some participants felt that even if a man did not divorce an uncut woman, he would demand that she is cut after she delivers the first baby. As a woman from Gedaref explained, "If the man found her [the wife] uncut, he will demand it from her and after she gives birth to the child he will tell the midwife to do it."

Women and girls fear stigma and isolation: Participants noted that FGM/C is important to protect girls from stigma and isolation. The following quotes illustrate participants' concerns about the stigma associated with being uncut:

"We practise FGM/C because we fear being called names like Ghalfa [derogatory term used for uncut women as a social sanction]."

Woman, urban Gedaref

"Here, when girl is Ghalfa she is not allowed to walk and sit with circumcised girls."

Young woman, rural Khartoum

"In my own mind because all people do this thing, it was difficult for us at the beginning to say no. But we accepted to say no. It was difficult at the beginning because people say to you this girl is not cut and the traditions say that she must be cut. She is not good this way. So, when this comes out from a few of us and then we all agree not to cut then we can stop."

Woman, rural Gedaref

"We cut our girls to prevent them from danger."

Woman, urban Khartoum

Although uncut young women were reported to face very powerful negative sanctions, stigma, and isolation, participants also noted that being cut could also bring fear and shame. For example, some participants explained that during their honeymoon, young women with the type III cut were sometimes brought to midwives or hospitals to be de-infibulated, hence spending their first weeks 
in marriage with an open wound. This was noted to have social implications as one of the young women from rural Khartoum explained:

"My cousin, after one week from the honeymoon, her husband brought her back to the family, complaining that he found her very tightly closed, and he could not penetrate. They took her to the doctor so as to increase the opening. She faced a hard experience... To increase her worries, she was the gossip for the family and neighbours and friends. From that day she became one of the main FGM/C fighters, conducted many awareness activities and discussions."

Moving to Khartoum or an urban area (from rural non-practising areas; mostly Western Sudan) was one of the factors cited as having an influence on the uptake of FGM/C or the change in attitudes towards it. Urbanisation and migration to Khartoum were noted to lead to changes in one's reference groups, environment, and exposure to new knowledge and experiences. According to participants, a woman being examined by a male doctor, as was reported to be the case in Khartoum, had to be 'clean'. According to these participants, FGM/C was necessary even for women from ethnic groups that do not traditionally practise, because male doctors would examine them. One of the women in Khartoum state explained:

"We moved to Khartoum and my daughter [a nurse] came for a course in Khartoum, so she told us all that women go to doctors in Khartoum and they see them naked, so they have to be clean. So, she cut all of us in the house, even me."

In the Umbadda area (urban Khartoum State), social pressure was reported to be the only driver of FGM/C among tribes from the Nuba Mountains, South Sudan, and parts of Darfur, who traditionally do not practise FGM/C. According to participants, families from these communities began to practise FGM/C due to intermarriage and social pressures to be like other women. These views are expressed in the following quotations:

"Families from South Sudan and Darfur did not practise FGM/C but once they moved to Khartoum and due to inter-marriage with other tribes in Khartoum, they adopted the practice."

Mother, urban Khartoum

"There was a man from the north who had married a southern Sudanese woman. That is only because she is not cut...but when she was giving birth she discovered that all the Arab women in the hospital were screaming ... she felt ashamed as they were screaming [making a crying sound]. She immediately requested the midwife to cut her so she can shout as they do."

Grandmother, rural Khartoum

Ethnicity and an adherence to tribal/cultural norms or identity were also noted to have an impact on the practice, especially among those living in ethnically homogenous communities. Most of these close-knit groups were noted to have no intention to stop or were not willing to stop the practice of $\mathrm{FGM} / \mathrm{C}$ due to social sanctions from other members of the tribe. According to participants, even when the supply of providers was scarce, people from these communities would still manage to find alternatives and sustain the practice of type III FGM/C, which was reported to be their tribal "mark", as stated below by some of the elderly women from urban Khartoum:

"Pharaonic circumcision [type III] is a strong part in our life and culture and we will not give it up. We inherited it from our grandmothers, even if the daughter's mother died then either the aunt or the grandmother will circumcise her."

"FGM/C is mandatory in our tribe. No girl is left uncircumcised in our tribe."

"We do pharaonic circumcision [type III] in our tribe and we do not leave our daughters uncircumcised." 


\section{Perceived Effects of the Law on FGM/C}

Although Gedaref State has a law banning FGM/C while Khartoum State is in the process of developing one, participants in Khartoum State were more apprehensive than those in Gedaref about the existence of a "law" that bans the practice of FGM/C in the state. For these participants, this "law" was one of the reasons why some families and HCPs, particularly midwives, are not practising FGM/C. As highlighted in the following narrative from a woman in Gedaref, the existence of the law in Gedaref State was believed to drive the practice underground:

"I did it [FGM/C] in my house. Long ago, at the time of Nimeiry [President of Sudan from 1969-1985] a girl's aunt went and called a midwife and they brought the girl in a taxi with her bag and they laid her in the prepared bed and cut her and we sang with the dalooka [traditional drum] and we celebrated. But now people say it is forbidden and things like this. People are afraid. They do not stop doing it. They will do it secretly."

The social disapproval associated with reporting family members who break the "law" was also highlighted. As one woman from Khartoum explained:

"Originally, I was not accepting that she cuts my daughters. When my mother [the haja], had them cut, I was not in the house and came back to find that the traditional midwife had cut them already. I asked her, 'Why, haja, why did you do it?' She said, 'I did it and whatever you want to do, do it. They are jailing people now and if you want to send me to jail, do it'. I told her that no one sends her mother to jail and I kept quiet and left her alone."

\section{Perceived Effects of the Midwifery Oath on FGM/C}

All interviewed participants noted that many midwives were refusing to perform FGM/C, especially the type III cut, due to the oath that midwives are expected to take as part of their professional code of conduct. Explaining that families had to rely on midwives from other areas because of the oath, one woman from rural Khartoum noted, "the midwife that circumcises our daughters is not from our place as all the available ones do not perform FGM/C due to the oath." The midwifery oath also emerged as a reason why many participants were cautious about revealing who had cut their daughters. They often referred to "that midwife" and when probed for more details about her whereabouts, most respondents indicated that she had left the area, that she had died, or she was not from the area.

In areas where midwives refuse to perform $\mathrm{FGM} / \mathrm{C}$, families were reported to take their girls to a TBA or dayat aljabal (the mountain midwife) as they called her. In other cases, they brought a trained midwife from a different area to perform FGM/C. As noted by a mother from rural Khartoum,

"A midwife came from another place to circumcise the daughters of our neighbour. My daughters were taken to that midwife. They were circumcised in the house of our neighbour. Usually, the family calls the midwife who is from another area to come and circumcise their daughters."

For some midwives, the oath was reportedly viewed as a vow between them and Allah, which made them take the oath seriously. However, others indicated that midwives avoided saying the exact words related to FGM/C or lowered their hands during this part of the oath so that they would not be held accountable or would not be punished by Allah. Explaining this point, a midwife from rural Gedaref noted:

"All the midwives in [rural Gedaref] took the oath. But during the oath they did not say the exact words thinking that the oath will not be real unless they place their hands on the Holy Quran, otherwise it is not an oath. But they also said, 'we will cut' so that they can allow themselves income from the FGM/C and re-infibulation as their income from a government salary is little." 


\section{Perceived Drivers of the Shift in the Type of FGM/C}

According to some participants, less severe forms of the cut (presumably type I) are not considered to be FGM/C and in some areas where type III is practised, this "lesser cut" was reportedly considered as incomplete FGM/C or not cutting. Further, the fact that type I in Sudan is often referred to as the Sunna cut, means that many people believed that type I is religiously required and approved. As such, even when people stopped practising type III, they were reportedly likely to practise type I. Explaining the perceived religious basis for type I FGM/C, a father from Gedaref stated:

"We do Sunna, which is the Sunna [teaching] of Prophet Mohamed [PBUH] and he told UmiAtia [a woman in his time] not to cut much and leave parts as they are. This is the Sunna. We should do it."

The perception that type I has no complications and was safer was also reported to drive the shift from the pharaonic type. Explaining why people in her community prefer the type I cut, a young woman in Gedaref State said, "Al Sunna [type I] has no effect like the pharaonic type [type III] which causes infections and makes women unable to have children." Similarly, a father from rural Khartoum State described the lengthy recovery period following a type III cut and indicated that he had told his wife that his daughters would only undergo the type I cut:

"The pharaonic circumcision puts women in great problems as they stay in bed for 40 days. I have suffered as I had to do house chores and cook. I told her to do type I only for the girls. Women with type I stay in bed for a week and then move around. The future for women is in type I."

Other factors noted to influence the shift in the severity of cutting included the preferences of others in one's social network and reference groups and the existence of educational and awareness efforts, especially in urban areas. Women who were against FGM/C but who were forced to undergo the cut were also reported to resort to less severe cutting. Finally, the midwifery oath and awareness about the law, even in Khartoum State, where there is no law, were also noted to be drivers of the shift in the severity of cutting.

\section{Perceived Drivers of the Shift in the Age of FGM/C}

Few participants referred to a shift in the age of cutting. For some, the cutting of girls at a very young age, such as three years, was because mothers were told that it would improve the health status of their girls. However, one of the men from Gedaref believed that undergoing the cut at an older age (older than nine years) instead of three to four years would minimise health risks and reduce bleeding. In Gedaref, an upward shift in the age of cutting from five years to 11 or 12 years was noted. This shift was reported to stem from a need for girls to show their maturity so that they could get husbands.

In Khartoum State, the age of cutting was noted to vary by ethnicity. For example, girls from the Gamoeia ethnic group were reportedly cut when aged six to nine years and often during the school holidays. A mother from the Meloha ethnic group (an Arab ethnic group), which lives close to the Gamoeia, reported that girls are cut immediately after birth or a week following birth. She explained:

"We cut our girls in the Semaya [naming] part or in the Sebooa [seventh day celebration] so we can have the same midwife to do the birth and the circumcision."

\section{Perceived Drivers of the Medicalisation of FGM/C}

Traditionally, FGM/C was performed by TBAs. However, we found that people were increasingly turning to HCPs to perform FGM/C. Reasons for this increase in medicalisation included changes in people's reference groups and social networks due to migration, and the availability of practising 
HCPs. Some participants also noted that women who were against FGM/C but who were forced to undergo the procedure would resort to medicalisation.

Health campaigns were also reported to play a part in influencing medicalisation as people believe that the risks of FGM/C are lower if HPCs perform the cut. Mothers reportedly preferred having doctors perform FGM/C as they are more knowledgeable and will not cause harm to their daughters. Perceptions that doctors are "safe performers" was noted to drive a new "social norm". As such, there was a general belief that if HCPs abandon FGM/C, many people would abandon the practice, resulting in less demand. As a woman in Khartoum State noted, "Doctors are knowledgeable and do the right thing. If doctors say to us, 'Circumcise,' then we will do it because if circumcision is not good they will not do it." Some participants felt that medicalisation would be more common if female doctors performed FGM/C.

Health care providers, and especially those who perform type III, as was reportedly the case in rural Khartoum, influence the continued practice of FGM/C. Indeed, some HCPs indicated that they were merely responding to demands from the families for $F G M / C$, believing that if they did not fulfil these demands, families would go to traditional practitioners and get the type III cut. Some HCPs also noted that they were knowledgeable about the health hazards of FGM/C. As a midwife from Khartoum State noted, "The doctor and midwife have something to give to the child they want to circumcise, but the traditional midwife, I do not know, she may have nothing to give as treatment."

Some midwives were also noted to believe that FGM/C is a tradition and belief. For these midwives, refusing to perform FGM/C was believed to result in negative sanctions by their community and peers. Negative sanctions against midwives who refused to perform FGM/C were also reported by community members as a woman from rural Khartoum explained:

"We bring the dayat aljabal [traditional midwife] to cut our daughters and when we want to deliver we bring our relative from Omdurma. The midwife we have here does not cut the girls and so we do not talk to her or invite her to anything. She has lived here with us for twenty years but does not want to do things for us."

\section{Perceptions of Interventions that are Effective in Reducing Medicalisation and Promoting FGM/C Abandonment}

Participants were asked to share their insights on interventions that they believed were effective in reducing medicalisation and promoting FGM/C abandonment in their communities. While some participants were very confident that the practice would and should continue because it is a favourable and "useful" practice for girls, others highlighted a number of interventions including: awareness raising lectures and events, particularly in rural areas; the involvement of the government and media in FGM/C abandonment campaigns; enforcement of the law against FGM/C; and strengthening the role of school teachers, who were perceived to be effective in educating young girls who, in turn, were believed to have a role in convincing families to abandon the practice. Underscoring the latter, a father in Khartoum noted, " "When I wanted to cut my nineyear-old daughter she refused and threatened to call the police and I left her uncut." Similarly, a father in Gedaref explained the importance of empowering young girls and boys to become future advocates against $F G M / C$ by stating:

"My daughter refused FGM/C and she said to me, 'My teacher in school gave us a session about FGM/C and said it's a harmful practice and has several complications in the future and...I want to be Saleema' [an Arabic word meaning 'whole, healthy, and perfect' that is used as a positive descriptor of an uncut girl]." 


\section{Discussion}

The focus of the study was to identify the drivers of the medicalisation of FGM/C in Sudan. The study was carried out in two states, Khartoum and Gedaref, which have diverse populations and different levels of medicalisation. Gedaref has a law banning FGM/C while Khartoum does not. Drawing on the social norms theory, we examined some of the links that exist between different social, legal, religious, and gender aspects of $\mathrm{FGM} / \mathrm{C}$ and the impact they have on medicalisation of the practice and the drivers of its continuation.

Three important elements were examined; shifts and change in type, age, and performers of FGM/C; drivers of medicalisation; and the impact and role of reference groups and social networks in the continuation of medicalisation. Figure 2 shows the different elements that were identified through the study.

Figure 2. Key elements of FGM/C practice in Sudan

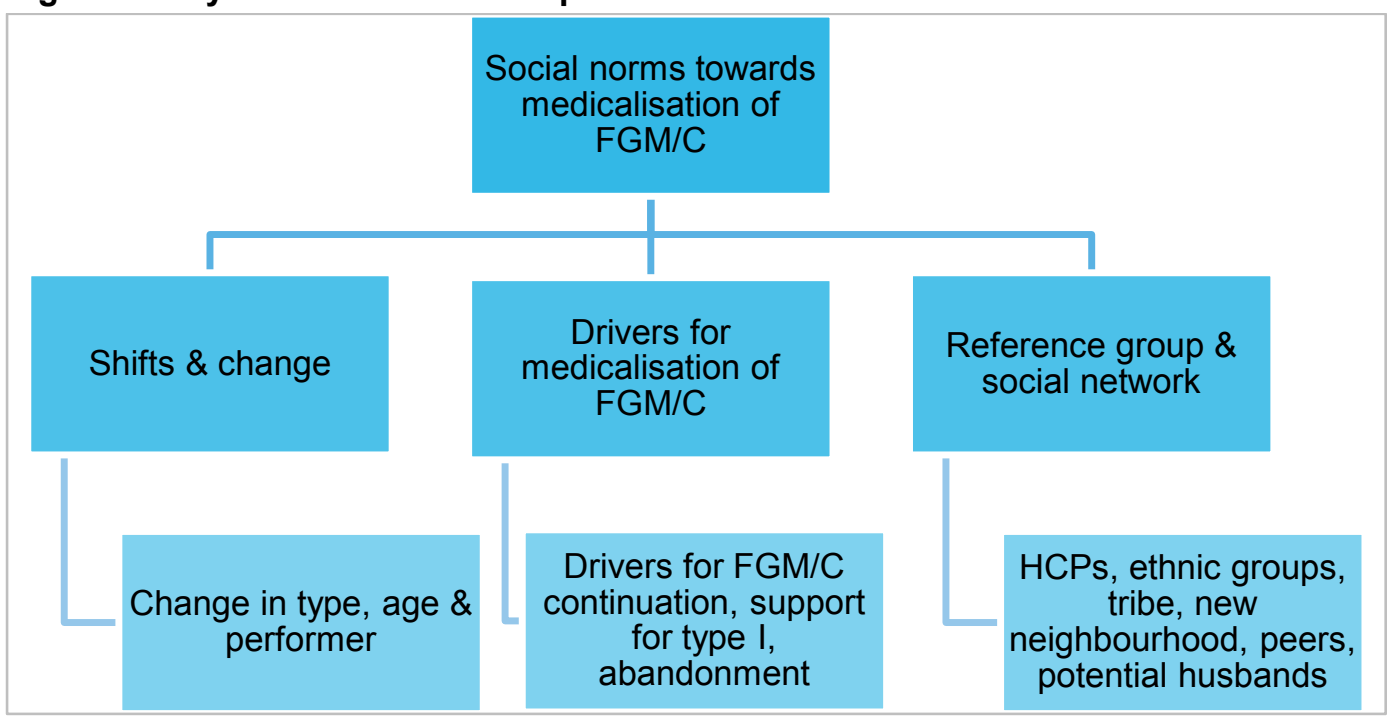

We found that FGM/C is a deeply rooted practice that is maintained by the existing gender disparities in society and beliefs of preserving a girl's purity and modesty, and controlling women's sexuality. FGM/C is very much linked to marriageability and sustained by older generations to ensure that younger ones conform to being marriageable as failing to do so will expose them to social stigmatisation (UNICEF, 2013). Our study has reiterated and shown that marriageability is a common driver, not only for the continuation of $\mathrm{FGM} / \mathrm{C}$, but also for the involvement of HCPs in the practice. There is an assumption that there is a high demand for the services of HCPs and that offering $\mathrm{FGM} / \mathrm{C}$ services enables families to gain social respect through marrying their daughters off. Both women and HCPs in this study indicated their belief that FGM/C has benefits for the girl and protects her from unacceptable sexual conduct, as well as promotes individual cleanliness. Previous studies in other countries have also indicated that FGM/C is associated with cleanliness and beauty among girls due to the removal of body parts that are considered unclean, unfeminine, or male (Berg \& Denison, 2013). For those who may not believe in the value of FGM/C, societal/ familial pressure may be more important than personal choice or preference.

The shift to less severe cutting is evident in our study and is sustained by both the involvement of HCPs in the practice and the religious notion attached to it. Literature often attributes increased prevalence of type I in Sudan to the religious connotation of it (El-Tom, 1998). However, in our study, the issue of HCPs advocating for less severe cutting and the general belief that it is less harmful exposes a new dimension. This could be attributed to the ongoing national campaign on 
FGM/C and the continued implementation of campaigns that emphasise the risks of the severe type III.

National surveys show that most FGM/C procedures are performed by health workers, such as midwives, nurses, or doctors (SHHS, 2010). In our study, a similar pattern was found. Cases where TBAs or circumcisers were sought were mostly due to the refusal of HCPs, especially midwives, to perform FGM/C or to perform type III FGM/C.

Despite the long-standing campaign in Sudan, there is no national legislation against FGM/C (UNICEF, 2013; PRB, 2013). However, a law exists in Gedaref State, though not yet effectively enforced. There is no law banning FGM/C in Khartoum State. Yet, our participants in this study were "aware" of a law banning FGM/C in Khartoum. The fear of the law may result in the practice going underground and may make it harder for behaviour change intervention programmes to meaningfully engage people.

Few participants in our studies reported a shift in the age at cutting. The direction of this shift varied with some communities reportedly cutting at younger ages to minimise health risks. Unlike other studies that have similarly reported a shift towards cutting at younger ages (Powell and Yussuf, 2018), we also found that some communities were reportedly cutting girls at an older age to reduce health risks or to prepare girls for marriage.

\section{Limitations}

This study has several limitations. First, given the sensitivities around FGM/C, some participants may have felt uncomfortable answering questions. Indeed, some inconsistencies were observed between women's and HCPs' reports about medicalised FGM that may have stemmed from fear about the illegality of FGM/C. Second, the study results cannot be generalised to all populations in the two states as there are specific contextual drivers for other communities that may not have been captured.

\section{Conclusions}

The practice of FGM/C, while still prevalent in Sudan, is undergoing several shifts including changes in the type of FGM/C and increasing medicalisation. Study findings show that the shift to less severe cutting in some communities is driven, in part, by social and religious norms about the importance of $\mathrm{FGM} / \mathrm{C}$ coupled with an increased awareness of the health consequences of $\mathrm{FGM} / \mathrm{C}$. The awareness of the health consequences of FGM/C also drives the medicalisation of the practice and increases the demand for, and social pressure on, health providers to perform FGM/C. Midwives' refusal to perform FGM/C, particularly type III, is also believed to drive the shift to less severe forms of FGM/C. Study findings underscore the need for training programmes to increase HCPs' awareness of FGM/C and for strong peer support systems from other health workers to counter the increased demand for medicalisation. Interviews with mothers also suggest that some of them are protective of HCPs who perform FGM/C, which has implications for enforcement of laws targeting providers. Study findings also suggest that enforcing a punitive law against $\mathrm{FGM} / \mathrm{C}$ may reduce the practice but could also drive the practice underground. 


\section{Implications}

As outlined below, study findings provide useful insights for programmes and policies aimed at promoting the abandonment of FGM/C. Study findings also highlight several areas where further research may be warranted.

\section{Policy Implications:}

- Continue support for FGM/C abandonment in professional codes of conduct for HCPs.

\section{Programmatic Implications}

- Integrate FGM/C in school curricula and programmes and continue the provision of information of $\mathrm{FGM} / \mathrm{C}$ in the pre-licence training of paramedical personnel and midwives.

- Effectively target men, particularly younger men, in FGM/C abandonment interventions.

- Enhance the training of medical doctors on FGM/C, particularly female doctors who may face increased demand for FGM/C services.

- Continue to implement programmes that increase community awareness of the hazards of all types of FGM/C, including type I. These programmes should also address the religious underpinnings of the practice, including perceptions that type I FGM/C is Sunna.

\section{Research Implications}

- Conduct research among younger men to understand their attitudes towards FGM/C and how they can be effectively reached in FGM/C abandonment programmes.

- Conduct research to identify the positive deviants among providers who have abandoned the practice, their drivers, and the scope of their influence. Whether and how this deviance can be replicated in other contexts should also be investigated.

- Examine how shifts in age of cutting relate to apparent shifts in prevalence in cohorts and interrogate what this means in terms of identifying states with high prevalence for future interventions. 


\section{References}

28 Too Many. (2018). Sudan: the law and FGM. London: 28 Too Many. Retrieved 19 September, 2018, from

https://www.28toomany.org/static/media/uploads/Law\%20Reports/sudan_law_report_v1_(j uly_2018).pdf

Abdulcadir, J., Margairaz, C., Boulvain, M., \& Irion, O. (2011). Care of women with female genital mutilation/cutting. Swiss Medical Weekly. http://dx.doi.org/10.4414/smw.2011.13137

Banks, E., Meirik, O., Farley, T., Akande, O., Bathija, H., \& Ali, M. (2006). Female genital mutilation and obstetric outcome: WHO collaborative prospective study in six African countries. The Lancet, 367(9525), 1835-1841. http://dx.doi.org/10.1016/s01406736(06)68805-3

Bedri, N. (2013) Evidence based advocacy for ending FGM/C in Sudan. Ahfad Journal, 30(1), 921.

Berg, C., Underland, V., Odgaard-Jensen, J., Fretheim, A., \& Vist, E. (2014). Effects of female genital cutting on physical health outcomes: a systematic review and meta-analysis. BMJ Open, 4(11). http://dx.doi.org/10.1136/bmjopen-2014-006316

Berg, R. C., \& Denison, E. (2013). A tradition in transition: factors perpetuating and hindering the continuance of female genital mutilation/cutting (FGM/C) summarized in a systematic review. Health Care for Women International, 34(10), 837-859.

https://doi.org/10.1080/07399332.2012.721417

Central Bureau of Statistics (CBS) \& UNICEF Sudan. (2016). Multiple Indicator Cluster Survey 2014 of Sudan, Final Report. Khartoum, Sudan: UNICEF and CBS.

Cochran, W. (1977). Sampling Techniques, 3rd Edition. New York: John Wiley \& Sons, Inc.

Cook, R. J., Dickens, B. M., \& Fathalla, M. F. (2002). Female genital cutting (mutilation/circumcision): ethical and legal dimensions. International Journal of Gynecology and Obstetrics, 79(3), 281-287. https://doi.org/10.1016/S0020-7292(02)00277-1

El-Tom, A. O. (1998). Female circumcision and ethnic identification in Sudan with special reference to the Berti of Darfur. GeoJournal, 46(2), 163-170.

https://doi.org/10.1023/A:1006946112003

Gamal, A., \& Hussein, F. (2013). Decision making study in Khartoum State. GRACe Research report. AUW \& UNFPA

Gibeau, A. M. (1998), Female genital mutilation: when a cultural practice generates clinical and ethical dilemmas. Journal of Obstetric, Gynecologic, \& Neonatal Nursing, 27: 85-91. doi:10.1111/j.1552-6909.1998.tb02595.x

Kelly, E., \& Hillard, P. (2005). Female genital mutilation. Current Opinion in Obstetrics and Gynecology, 17(5), 490-494. http://dx.doi.org/10.1097/01.gco.0000183528.18728.57

Lavazzo, C., Sardi, T., \& Gkegkes, I. (2013). Female genital mutilation and infections: a systematic review of the clinical evidence. Archives of Gynecology and Obstetrics, 287(6), 1137-1149. http://dx.doi.org/10.1007/s00404-012-2708-5

Odukogbe, A.-T. A., Afolabi, B. B., Bello, O. O., \& Adeyanju, A. S. (2017). Female genital mutilation/cutting in Africa. Translational Andrology and Urology, 6(2), 138-148. https://doi.org/10.21037/tau.2016.12.01 
Pearce, A. J., \& Bewley, S. (2014). Medicalization of female genital mutilation. Harm reduction or unethical?. Obstetrics, Gynaecology \& Reproductive Medicine. 24(1), 29-30. https://doi.org/10.1016/j.ogrm.2013.11.003

Population Reference Bureau. (2013). Ending female genital mutilation/cutting: lessons from a decade of progress. Retrieved 31 December, 2017, from http://www.prb.org/pdf14/progress-ending-fgm.pdf

Powell, R.A., \& Yussuf, M. (2018). Changes in FGM/C in Somaliland: medical narrative driving shift in types of cutting. Evidence to End FGM/C: Research to Help Women Thrive. New York: Population Council.http://www.popcouncil.org/uploads/pdfs/2018RH FGMCSomaliland.pdf

Rushwan, H. (2013). Female genital mutilation: a tragedy for women's reproductive health. African Journal of Urology, 19(3), 130-133. http://dx.doi.org/10.1016/j.afju.2013.03.002

Serour, G. (2010). The issue of reinfibulation. International Journal of Gynecology \& Obstetrics, 109(2), 93-96. http://dx.doi.org/10.1016/j.ijgo.2010.01.001

Sudan Household and Health Survey (SHHS). (2010). Sudan Household Health Survey. Khartoum: Federal Ministry of Health \& Central Bureau of Statistics. Retrieved on 31 December, 2017, from http://reliefweb.int/sites/reliefweb.int/files/resources/MICS4 Sudan 2010.pdf

Toubia, N. (1994). Female circumcision as a public health issue. New England Journal of Medicine, 331(11), 712-716. https://doi.org/10.1056/NEJM199409153311106

U.S Department of State. (2001). Female genital mutilation (FGM) or female genital cutting (FGC): Individual Country Reports. 2001-2009.state.gov. Retrieved 30 December, 2017 from https://2001-2009.state.gov/g/wi/rls/rep/crfgm/

UNICEF, \& European Union. (2010). The dynamics of social change: towards the abandonment of female genital mutilation/cutting in five African countries. Insight. Retrieved from http://www.unicef-irc.org/publications/618

United Nations Children's Fund (UNICEF). (2013). Female genital mutilation/cutting: a statistical overview and exploration of the dynamics of change. New York: UNICEF. Retrieved from https://www.unicef.org/media/files/UNICEF_FGM report_July_2013 Hi res.pdf

United Nations Children's Fund (UNICEF). (2016). Female genital mutilation/cutting (FGM/C) and child marriage in Sudan - are there any changes taking place? An in-depth analysis using Multiple Indicators Cluster Surveys (MICS) and Sudanese Household and Health Surveys (SHHS) UNICEF. Retrieved from

https://www.unicef.org/sudan/MICS Secondary Analysis FGMC CM English Version FI NAL FINAL.pdf

United Nations Children's Fund (UNICEF). (2016). Female genital mutilation/cutting: a global concern. UNICEF. Retrieved from https://www.unicef.org/media/files/FGMC 2016 brochure final UNICEF SPREAD.pdf

United Nations Children's Fund (UNICEF). (2014). Female genital mutilation/cutting: what might the future hold? New York: UNICEF. Retrieved from https://www.unicef.org/media/files/FGM-C_Report_7_15 Final_LR.pdf

United Nations Population Fund (UNFPA). (2014). Achieving equality in maternal health in the Arab region: Policy brief. UNFPA-ASRO. 
United Nations Population Fund (UNFPA), \& United Nations Children's Fund (UNICEF). (2014). UNFPA-UNICEF Joint Programme on Female Genital Mutilation/Cutting: Accelerating Change (pp. 1-52). New York: United Nations Population Fund and United Nations Children's Fund. Retrieved from http://www.unfpa.org/publications/unfpa-unicef-jointprogramme-female-genital-mutilationcutting-accelerating-change

United Nations Population Fund (UNFPA). (2011). A situational assessment of health sector role/interventions in female genital mutilation/cutting in Khartoum State, Sudan-final report.

World Health Organization (WHO), United Nations Children's Fund (UNICEF), \& United Nations Population Fund (UNFPA). (1997). Female genital mutilation: a joint WHO/UNICEF/UNFPA statement. Geneva: World Health Organization. Retrieved from http://www.who.int/iris/handle/10665/41903

World Health Organization (WHO). (2006). New study shows female genital mutilation exposes women and babies to significant risk at childbirth. Who.int. Retrieved 29 December, 2017, from http://www.who.int.mediacentre/news/releases/2006/pr30/en/

World Health Organization (WHO). (2017). Female genital mutilation factsheet. Retrieved December 29, 2017, from http://www.who.int/mediacentre/factsheet/fs241/en/ 